\title{
Multimodality Imaging Evaluation of Spinal Trauma with Epidemiological and Demographical Analysis in a Tertiary Care Hospital of Northern India
}

\author{
Vineet Tomar ${ }^{1}$, Sonal Saran², Prashant K Gupta ${ }^{3}$ \\ ${ }^{1}$ Resident, Department of Radiology, Subharti Medical College, Meerut, UP, ${ }^{2}$ Assistant Professor, Department of Radiology, \\ Subharti medical College, Meerut, UP, ${ }^{3}$ Former Professor and Head, Department of Radiology, Subharti Medical College, \\ Meerut, UP, India
}

Corresponding author: Dr Sonal Saran, Assistant Professor, Department of Radiology, Subharti medical college, Meerut, UP, India

DOI: http://dx.doi.org/10.21276/ijcmsr.2019.4.1.12

How to cite this article: Vineet Tomar, Sonal Saran, Prashant K Gupta. Multimodality imaging evaluation of spinal trauma with epidemiological and demographical analysis in a tertiary care hospital of Northern India. International Journal of Contemporary Medicine Surgery and Radiology. 2019;4(1):A47-A52.

\section{A B S T R A C T}

Introduction: Traumatic spinal cord injuries are often accompanied by devastating outcomes with significant neurological damage which is potentially preventable. Rapid Imaging diagnosis and treatment can prevent progression from incomplete injury to complete and debilitating one. Study aimed to evaluate the epidemiologic, demographic and clinical profile of patients with Traumatic spinal cord injuries, and to evaluate the level and pattern of spinal trauma with the help of Conventional Radiography, CT and MRI.

Method and materials: This prospective study of 108 patients, who presented with provisional diagnosis of Traumatic spinal cord injuries, was carried out in the Department of Radio-diagnosis at our institute. Patients with history of previous spinal surgery and having contraindications for MRI were excluded. Clinical examination was done by the experienced clinicians and American Spinal Injury Association Impairment Scale was recorded. Imaging studies were performed and findings were recorded.

Results: The mean age at injury was 43.45 years (48.05years for males and 30.5 years for females). Male to female ratio was 1.8:1. A total of $40.74 \%(n=44)$ of the spinal injured had other associated non spinal injuries. Out of 108 cases, 11 cases $(10.18 \%)$ were of Spinal cord injury without radiographic abnormality and 5 cases had Spondylolisthesis without evidence of fracture. Vertebral fractures were detected in 92 cases. Spondylolisthesis was seen in 17 cases with anterolisthesis accounting for 14 and posterolisthesis for 2 cases, whereas lateral listhesis was seen in one patient with complete cord cutoff. Upper cervical (C1-C3), lower cervical (C4-7), thoracic (T1-10), thoracolumbar (T11-L1) and lumbar (below L1) regions accounted for $5.93 \%, 18.64 \%, 15.25 \%, 38.98 \%$ and $19.49 \%$ of the vertebral injuries, respectively.

Conclusion: Early radiological diagnosis of the level of fracture, displacement of fractured fragments into the spinal canal, stability of spinal column, involvement of spinal cord and nerve roots is very important for early surgical interventions and prevention of the debilitating outcomes.

Keywords: Multimodality Imaging Evaluation of Spinal Trauma, Epidemiological, Demographical Analysis

\section{INTRODUCTION}

Traumatic spinal cord injuries [TSCI] are often accompanied by devastating outcomes with significant neurological damage which is potentially preventable. Rapid diagnosis and treatment can prevent progression from incomplete injury to complete and debilitating one. Imaging studies are necessary to know the exact site of trauma, spinal stability and compression over spinal cord and nerve roots. $^{1}$

Worldwide, most common cause of spinal trauma is road traffic accident (RTA) accounting for $40 \%$ of reported cases, other causes being fall from height (FFH) and sports injuries. $^{2}$ Increase in motorized vehicles along with expansion of the road network is largely responsible for upsurge of RTAs in India. ${ }^{3}$ According to the World Health Organization (WHO), RTAs are the sixth leading cause of death in India mainly affecting young and middle aged people leading to adverse socioeconomic impact. ${ }^{4}$ Deaths due to RTAs are expected to be around 1.9 million per year by 2020 if no preventive measures are taken. ${ }^{5}$

In early 1990s, the evaluation of the spinal trauma was limited to the Conventional Radiography of the spine with multiple views for the optimal assessment, however the advent of Multidetector Computerized Tomography (MDCT) has revolutionized the imaging of spinal trauma. MDCT allows faster acquisition with thin collimation and multiplanar 
display and has replaced conventional radiography in almost all centers wherever it is available. It allows three dimensional reconstruction for improved visualization of the injuries. Simultaneous use of contrast medium can help in diagnosing vascular injuries in the cervical region. Magnetic resonance imaging (MRI) is indicated in some cases of spinal trauma where detailed information about soft tissue structures is required. Evaluation of intervertebral disc, ligaments, intramedullary space, intradural extramedullary space, extradural space, paravetebral soft tissue and muscles are better evaluated with the help of MRI. MRI can add vital information and influence the treatment options and outcomes in certain situations like traumatic disc herniation, expanding extramedullary hematomas compressing the spinal cord, cord edema, myelomalacia and syrinx formation, in which CT may not be helpful. Clinical examination is often unreliable in spinal trauma patients and increasingly liberal utilization of imaging resources is required for its evaluation. ${ }^{6}$

Study aimed to evaluate the epidemiologic, demographic and clinical profile of patients with TSCI, and to evaluate the level and pattern of spinal trauma with the help of Conventional Radiography, CT and MRI.

\section{METHOD AND MATERIALS}

This prospective study of 108 patients, who presented with provisional diagnosis of TSCI was carried out in the Department of Radio-diagnosis at our institute. Informed consent was obtained from all the patients. Patients with history of previous spinal surgery and having contraindications for MRI were excluded.

Total 137 patients of suspected spinal trauma were referred to our department for imaging evaluation. Out of those 137 patients, 29 cases were excluded as per exclusion criterion and only 108 patients were taken up for the study. Clinical examination was done by the experienced clinicians and American Spinal Injury Association (ASIA) Impairment Scale (AIS) was recorded. Data which were recorded are tabulated in Table 1.

Plain Radiography: Standard radiographic exposure of cervical, thoracic and lumbo-sacral region were taken in anteroposterior and lateral view as per indication. Any specific view was also taken, as and when required.

Computerized Tomography: CT was conducted in those cases where there was doubt of fracture on conventional radiography or there were clinical symptoms of spinal trauma with normal roentgenogram. CT was also conducted to evaluate other associated traumatic injuries of chest and abdomen. Patients were subjected to 128 slices, Philips Ingenuity Core MDCT unit.

Magnetic Resonance Imaging: MRI examination was conducted for further evaluation if diagnosis was not confirmatory by clinical, radiographic and CT examination. Following MRI sequences were taken:

a. Sagittal T1weighted, T2 weighted, Short tau inversion recovery (STIR) sequences,

b. Axial T1 weighted and T2 weighted sequences,

c. Coronal STIR sequence, and

d. Myelography.

\begin{tabular}{|l|l|}
\hline S No. & Data recorded \\
\hline 1 & $\begin{array}{l}\text { American Spinal Injury Association (ASIA) Impairment } \\
\text { Scale (AIS) } \\
\text { A: Complete } \\
\text { No motor or sensory function in the lowest sacral } \\
\text { segment (S4-S5) } \\
\text { B: Incomplete } \\
\text { Sensory function below neurologic level and in S4-S5, } \\
\text { no motor function below neurologic level } \\
\text { C: Incomplete } \\
\text { Motor function is preserved below neurologic level } \\
\text { and more than half of the key muscle groups below } \\
\text { neurologic level have a muscle grade less than 3. } \\
\text { D: Incomplete } \\
\text { Motor function is preserved below neurologic level } \\
\text { and at least half of the key muscle groups below } \\
\text { neurologic level have a muscle grade 3. } \\
\text { E: Normal } \\
\text { Sensory and motor function is normal }\end{array}$ \\
\hline 8 & Geographical location - rural/urban distribution \\
\hline 3 & Age, \\
\hline 4 & Gender, \\
\hline 5 & Marital status, \\
\hline 10 & Educational level, \\
\hline Vocational status, \\
\hline Dabltime and month of injury, \\
\hline 11 & $\begin{array}{l}\text { Height of fall in cases of FFH: low (less than 3 feet), } \\
\text { high }\end{array}$ \\
\hline Type and level of injury \\
\hline 12
\end{tabular}

\begin{tabular}{|l|c|}
\hline ASI scale & $\begin{array}{c}\text { No of subjects with scale at the time of } \\
\text { presentation }\end{array}$ \\
\hline A & $41(37.9 \%)$ \\
\hline B & $23(21.29 \%)$ \\
\hline C & $17(15.74 \%)$ \\
\hline D & $16(14.81 \%)$ \\
\hline E & $11(10.18 \%)$ \\
\hline \multicolumn{2}{|c|}{ Table-2: Distribution of TSCl patients according to ASI scale. } \\
\hline
\end{tabular}

\section{RESULTS}

A total of $51.85 \%(n=56)$ of the subjects with TSCI were from the urban areas whereas $47.33 \%(n=51)$ were from rural areas. The status of $0.92 \%(n=1)$ could not be determined. The most commonly affected age groups were 20-29 years and 40-49 years, accounting for $44.44 \%(n=48)$ of the subjects in the study. The mean age at injury was 43.45 years (48.05years for males and 30.5 years for females). Male to female ratio was 1.8:1 (64.81\% [n=70] males and 35.18\% [n= 38] females). This disparity between males and females was more obvious in the 20-39 years age group, and gradually reduced with age. Male to female ratio before the age of 50 years was 2.45:1 while after the age of 50 was 1.05:1. 


\begin{tabular}{|l|c|c|c|c|}
\hline Vertebral level & RTA & FFH & Others & Total \\
\hline C1 & 1 & 0 & 0 & 1 \\
\hline C2 & 4 & 0 & 2 & 6 \\
\hline C3 & 0 & 0 & 0 & 0 \\
\hline C4 & 3 & 2 & 0 & 5 \\
\hline C5 & 4 & 1 & 0 & 5 \\
\hline C6 & 6 & 1 & 1 & 8 \\
\hline C7 & 3 & 1 & 0 & 4 \\
\hline D1 & 3 & 0 & 0 & 3 \\
\hline D2 & 1 & 0 & 0 & 1 \\
\hline D3 & 2 & 0 & 0 & 2 \\
\hline D4 & 0 & 0 & 0 & 0 \\
\hline D5 & 0 & 1 & 0 & 1 \\
\hline D6 & 1 & 2 & 0 & 3 \\
\hline D7 & 3 & 0 & 0 & 3 \\
\hline D8 & 3 & 2 & 0 & 5 \\
\hline D9 & 1 & 0 & 0 & 1 \\
\hline D10 & 0 & 0 & 0 & 0 \\
\hline D11 & 4 & 4 & 1 & 9 \\
\hline D12 & 6 & 7 & 3 & 16 \\
\hline L1 & 11 & 8 & 2 & 21 \\
\hline L2 & 4 & 2 & 0 & 6 \\
\hline L3 & 3 & 2 & 1 & 6 \\
\hline L4 & 3 & 3 & 0 & 6 \\
\hline L5 & 1 & 1 & 0 & 2 \\
\hline Sacrum and coccyx & & & & 5 \\
\hline Table-3: Distribution of subjects on the basis of mode of injury \\
\hline
\end{tabular}

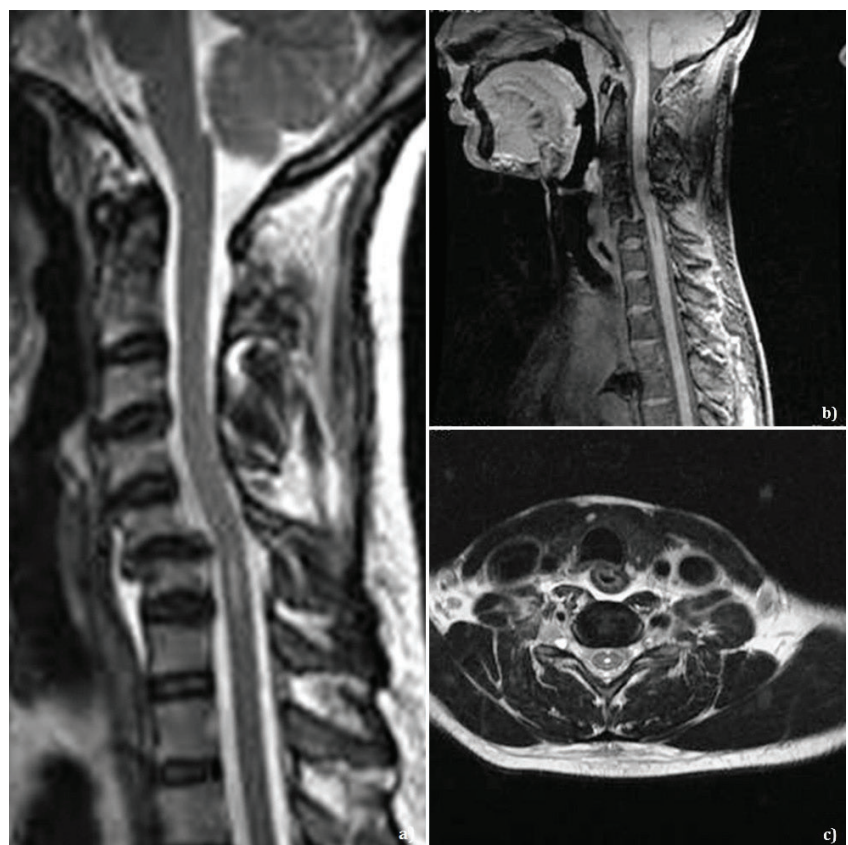

Figure-2: A 40 year old female patient with RTA underwent MRI which shows anterolisthesis of C5 over C6 well depicted on sagittal T2W and three-dimensional (3D) fast spoiled gradient-echo (FSPGR) sequences (a,b). A thin linear hyperintense area is seen within the spinal cord centrally extending vertically opposite C6 vertebral body, which is isointense to cerebrospinal fluid (a,c) suggestive of syrinx formed secondary to cord compression as a late sequela as patient came after 1 month of trauma due to the neurological deficit.
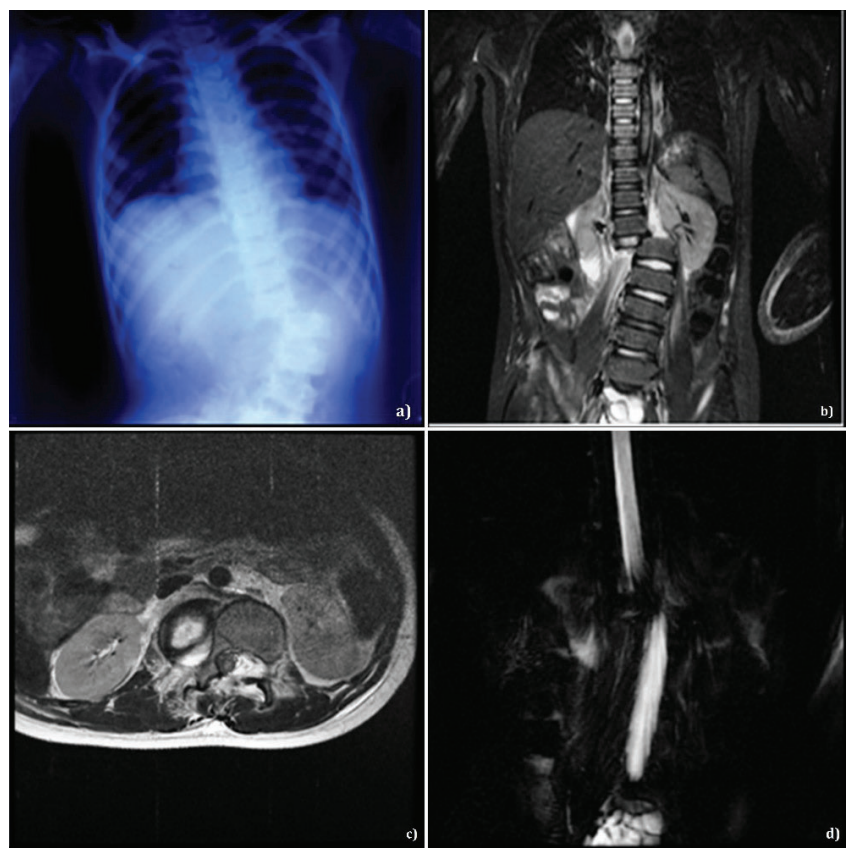

Figure-3: A 22 year old male patient with severe RTA showing grade IV right lateral listhesis of D12 over L1 well depicted on conventional radiograph (a). Coronal and axial T2 Weighted MRI images (b, c) showing similar finding with complete cutoff of spinal canal and cord. MR Myelography showing complete cutoff of the spinal column (d). 
At the time of injury $74.07 \%(n=80)$ were married, $12.03 \%$ $(\mathrm{n}=13)$ unmarried, 0.92\% ( $\mathrm{n}=01)$ divorced, 8.33\% ( $\mathrm{n}=09)$ widowed and $4.62 \%(n=05)$ were separated. Overall, $79.63 \%$ of persons with TSCI in the study were educated to at least matriculation and only $16.66 \%$ were illiterate.

Mostly RTA occurred on Mondays and Fridays probably because majority of people travel back to home on Fridays and to work on Mondays on National highway where our institute is situated. Busy roads and hurry in mindset leads to more accidents. Sixty percent $(n=64)$ of cases of TSCI occurred in winters (November-February), among which $59.3 \%(n=38)$ were due to RTA predominantly due to fog in this season.

A total of $40.74 \%(n=44)$ of the spinal injured had other associated non spinal injuries. Associated orthopedic injuries were the commonest $(52.38 \%, \mathrm{n}=22)$, followed by head injuries $(23.80 \%, \mathrm{n}=10)$, chest injuries $(21.42 \%, \mathrm{n}=9)$ and major visceral injuries $(7.14 \%, \mathrm{n}=3)$.

Distribution of TSCI cases according to ASI scale is shown in Table 2.

Out of 108 cases, 11 cases (10.18\%) were of Spinal cord injury without radiographic abnormality (SCIWORA) and 5 cases had Spondylolisthesis without evidence of fracture. Vertebral fractures were detected in 92 cases, out of which multiple vertebrae fractures were seen in 19 cases. Single vertebral fracture was seen in 73 cases, two vertebrae fracture are seen in 16 cases, one case had fracture of three vertebrae and two cases had fracture of five vertebrae. Spondylolisthesis was seen in 17 cases with anterolisthesis accounting for 14 and posterolisthesis for 2 cases, whereas lateral listhesis was seen in one patient with complete cord cutoff. Spondylolisthesis was most commonly seen in cervical vertebrae $(08 / 17$, 47.06\%). (Figure 1,2)

Upper cervical (C1-C3), lower cervical (C4-7), thoracic (T110), thoracolumbar (T11-L1) and lumbar (below L1) regions accounted for 5.93\% (7), 18.64\% (22), 15.25\% (18), 38.98\% (46) and $19.49 \%$ (25) of the vertebral injuries, respectively. Eleven patients had complete cord lesions involving the lower $\mathrm{C}$-spine (C4 to $\mathrm{C} 7$ ); 8 of these were motor vehicle related. Two patients had fracture of sacrococcygeal segments. RTA $(53.7 \%, n=58)$ and FFH $(37.04 \%, n=40)$ were the most common mode of injury. Sports and other causes accounted for $2.77 \%(n=3)$ and $6.48 \%(n=7)$ of injuries, respectively.

The study of 58 subjects with TSCI who had sustained injury as a result of RTA revealed that TSCI occurred in four-wheeled passenger vehicles like cars in $17.24 \%$ cases $(n=10)$, motorized two wheelers in $56.89 \%$ cases $(n=33)$, non-motorized transport users including pedestrians, three wheelers and cyclists (non-motorized two wheelers) in $12.07 \%(n=7), 5.17 \%(n=3)$ and $8.62 \%$ cases $(n=5)$ respectively.

The study of subjects with TSCI who had sustained injury due to $\mathrm{FFH}$ revealed that high falls i.e. more than 3 feet $(72.5 \%, \mathrm{n}=29)$ were more common as compared with low falls $(27.5 \%, n=11)$. Majority $65 \%(n=26)$ of falls were in the surroundings of their home with 'fall from roof' accounting for $22.5 \%$ cases $(n=9)$. Thoraco-lumbar followed by cervical level was most commonly affected in cases of falls. Fall into well was exclusively seen in females. Road traffic accident
(RTA), fall from tree, sports injuries were commoner in males.

Distribution of cases on the basis of etiology and level of vertebral fractures is described in Table 3.

\section{DISCUSSION}

The mean age at injury (43.45 years) in our study is more than that in studies from USA (37.6 years). ${ }^{7}$

The age distribution of patients is comparable with studies from the other parts of the India and World. Most common affected age group being 20-29 years signifying higher incidence in young, active and productive population of the society. ${ }^{7,8,9}$

The male female ratio (1.84:1) is much lower in our study as compared with that in other studies from across the globe $^{10}(3.8: 1)$ and some studies in the country. ${ }^{11,12,13}$ Higher incidence in males can be explained by examination of etiological factors, men being more exposed to risk factors since they are more active on account of occupation. Male to female ratio before the age of 50 years was $2.45: 1$ while after the age of 50 was $1.05: 1$, probably due to osteoporosis in elderly females accounting for fracture even after minor trauma.

A significantly higher percentage of TSCI, that is $74.07 \%$ were married at the time of injury in our study as compared with those in the studies from USA (30.6\%). ${ }^{14}$ This may reflect the lower mean age at which most Indians get married. ${ }^{15}$ Most other studies have not commented on the marital status.

Sixty percent of cases of TSCI occurred in winters (NovFeb.), among which 59.3\% were due to RTA. 23\% TSCI cases were from December. This might be because of fog and early sunset leading to poor visibility on roads and higher RTAs. RTA is the most common cause of injury in India ${ }^{16}$ and hence is expected to be the most common cause of TSCI as well. India is leading the world in number of deaths due to RTA according to first global status report on road safety by WHO. ${ }^{17}$ As per the National Crime Records Bureau, 14-15 people die every hour in road accidents in the country. ${ }^{18}$ Majority of patients were from lower and middle socioeconomic strata often belonging to rural areas. Due to lack of trained medical personnel and basic infrastructure in rural areas, initial management of spinal trauma patients is often delayed. The required initial immobilization is often not done which leads to significant neurological damage.

The study revealed that there were more accidents involving two wheeler vehicles like motorbikes (56.89\%) and four wheelers were second (17.24\%) followed by pedestrians (12.07\%). In South East Asia region, two-wheeler RTAs predominate as the major cause of TSCI. In contrast, the majority $(80 \%)$ of the RTA's in the National Spinal Cord Injury Statistical Center database ${ }^{7}$ were four wheeler automobile crashes, whereas motorcycles accounted for $13 \%$ cases. Cripps RA et al also revealed that major cause of TSCI in developed nations involved four wheeler automobile crushes. ${ }^{19}$ As two wheelers comprise $75 \%$ of total vehicles in India as compared to developed countries where these comprise only $5-10 \%$ of total vehicles, it is expected that motorized two wheelers are more likely to be involved in 
accidents in India. ${ }^{20}$

FFH was the second most common cause of TSCI in our study. Cases of FFH included fall from trees, electric pole, overloaded vehicle, fall from roof, fall into well, fall from animal, etc. Sports injuries accounted for only $2.77 \%(n=3)$ of TSCI cases in our study reflecting the lower popularity of sports as a hobby in India. Some sports like kite flying, high jump without cushions and Indian wrestling are played mainly in India and accounted for 3 injuries in our study. Rules and regulations for prevention of injuries in these sports need to be formed. Go BK et al revealed that sports and recreational activities have become much more frequent cause of TSCI (12.8\%) due to increase in variety of risky sports and leisure time activities. ${ }^{14}$ Violence (especially gunshot injuries) accounted for $2.77 \%$ of injuries in our study. Sutherland MW et al reported that violence has grown substantially in the past decade and account for $10-38 \%$ of TSCI. $^{21}$

Thoraco-lumbar region was the most common location to be involved in our study. Dorsal spine is fixed and supported by ribs whereas lumbar spine is more mobile and the junction is thereby most susceptible to trauma. Burke DA et al, Go BK et al and Karacan I et al reported cervical spine trauma to be the commonest followed by thoracic, thoraco-lumbar and lumbar region ${ }^{14,22,23}$ (Figure 3).

The commonest neurological level in our study were C6 (07.4\%), T11 (8.33\%), T12 (14.81\%) and L1 (19.44\%). According to NSCISC database C4 (12.7\%), C5 (15.7\%), C6 (12.6\%), C7 (6.3\%), T12 (7.6\%) and L1 (4.8\%) are most common neurological level. Tetraplegics and paraplegics accounted for $24.15 \%$ and $66.67 \%$ cases in our study. Wyndaele $\mathrm{M}$ et al reported tetraplegia to be more common in cases of TSCI. ${ }^{10}$

In our study, seven cases of neural arch fracture were present in cervical region which is highest in comparison to all other region. Yoo et $\mathrm{a}^{24}$ suggested that even minor trauma can lead to significant neurological damage if there is marked stenosis of cervical spinal canal. Being the most mobile segments of cervical spine, $\mathrm{C} 4-\mathrm{C} 7$ segments accounted for the most frequently fractured levels.

\section{CONCLUSION}

As there is tremendous epidemiological difference between India and developed countries, studies from abroad may not give an insight required for framing preventive strategies to decrease impact of spinal trauma in India. Very few specialized centers for spinal injuries in India are also responsible for profound impact of spinal trauma over lower and middle socioeconomic strata population. Abrupt onset of TSCI is very tragic for the patient as well as their families. Early radiological diagnosis of the level of fracture, displacement of fractured fragments into the spinal canal, stability of spinal column, involvement of spinal cord and nerve roots is very important for early surgical interventions and prevention of the debilitating outcomes. This also helps in explaining prognosis to the patients and his relatives. Conventional radiography is replaced by MDCT to the large extent all over the nation for evaluation of spinal trauma. MRI is highly efficient in diagnosing soft tissue, spinal cord and nerve roots injuries, however it is limited to higher centers in the urban areas. As our institute receives patients from vast area, it can show a trend towards which the epidemiology of spinal trauma is progressing, however further studies with even larger number of patients and involving more than one institute from different parts of country is required to compare demographical variation and thereby helping in framing effective preventive strategies.

\section{REFERENCES}

1. Parizel PM, van der Zijden T, Gaudino S, Spaepen M, Voormolen MH, Venstermans C, De Belder F, van den Hauwe L, Van Goethem J. Trauma of the spine and spinal cord: imaging strategies. Eur Spine J. 2010;19(Suppl 1):S8-17.

2. Parizel PM, Gielen JL, Vanhoenacker FM. The spine in sports injuries: the cervical spine. In: Vanhoenacker FM, Maes M, Gielen JL, editors. Imaging of orthopedic sports injuries. Berlin: Springer; 2007. pp. 377-390.

3. Road Accidents in India 2011. Transport Research Wing, Ministry of Road Transport and Highways, Government of India.

4. Ministry of Health and Family Welfare. Integrated Disease Surveillance Project- Project Implementation Plan 2004-2009. New Delhi: Government of India; 2004:1-18.

5. World Health Organisation. Road Traffic Injuries Fact Sheet N 0 358, March 2013. Available from: http:// www.who.int/mediacentre/factsheets/fs358/en.

6. Looby S, Flanders A. Spine trauma. Radiol Clin North [Am]. 2011;49(1):129-163.

7. National Spinal Cord Injury Statistical Center. "Spinal Cord Injury Facts and Figures at a Glance. Information Sheet" 2005.

8. Pickett W, Simpson K, Walker J, Brison RJ. Traumatic spinal cord injury in Ontario, Canada. J Trauma. 2003;55(6):1070-1076.

9. Dryden DM, Saunders LD, Rowe BH, May LA, Yiannakoulias N, Svenson LW et al. The epidemiology of traumatic spinal cord injury in Alberta, Canada. Can J Neurol Sci. 2003;30 (3):113-121.

10. Wyndaele M, Wyndaele JJ. Incidence, prevalence and epidemiology of spinal cord injury: what learns a worldwide literature survey? Spinal Cord. 2006;44 (1):523-529.

11. Agarwal P, Upadhyay P, Raja K. A demographic profile of traumatic and nontraumatic spinal injury cases: a hospital-based study from India. Spinal Cord. 2007;45 (4):597-602.

12. Singh R, Sharma SC, Mittal R, Sharma A. Traumatic spinal cord injuries in Haryana: an epidemiological study. Indian J Community Med. 2003;XXVIII (1):8486.

13. Shanmugasundaram TK. The care of SCI Patient in the Developing Nations- Can we stem the rot? Paraplegia. 1988;26 (2):10-11.

14. Go BK, DeVivo MJ, Richards JS. The epidemiology of spinal cord injury. In: Stover SL, DeLisa JA and Whiteneck GG (eds.) Spinal Cord Injury- Clinical Outcomes from the Model System. Aspen Publishers: Gaithersburg, MD, 1995, pp 21-55. 
15. United Nations, Population Division, Department of Economic and Social Affairs. World Marriage Patterns 2000, http:// www. un.org/ esa/population/ publications/world marriage/ world marriage patterns 2000.pdf

16. Kaul A, Sinha US, Pathak YK, Singh A., Kapoor AK, Sharma $S$ et al. Fatal road traffic accidents, study of Distribution, nature and type of injury.JIAFM. 2005;27 (3):71-76.

17. World Health Organization. Regional Report on Status of Road Safety: The South-East Asia Region. 2009.

18. National Crime Records Bureau, Ministry of Home Affairs. Accidents \& Suicides Clock-2009. Available at: http://ncrb.nic.in/CD-DSI2009/clock.pdf.

19. Cripps RA, Lee BB, Wing P, Weerts E, Mackay J, Brown D. A global map for traumatic spinal cord injury epidemiology: towards a living data repository for injury prevention. Spinal Cord. 2011;49 (1):493-501.

20. Gururaj G. Injuries in India: A national perspective. In: National Commission on Macroeconomics and Health. (eds) Burden of Disease in India; Equitable development-Healthy Future. Ministry of health and family welfare Government of India: New Delhi, 2005, pp 325-350.

21. Sutherland MW. The prevention of violent spinal cord injuries. SCI Nurs. 1993;1091-95.

22. Burke DA, Linden RD, Zhang YP, Maiste AC, Shields $\mathrm{CB}$. Incidence rates and populations at risk for spinal cord injury: a regional study. Spinal Cord. 2001;39 (6):274-278.

23. Karacan I, Koyuncu H, Pekel O, Sumbuloglu G, Kirnap $\mathrm{M}$, Dursum $\mathrm{H}$ et al. Traumatic spinal cord injuries in Turkey: a nationwide epidemiological study. Spinal Cord. 2000;38(11):697-701.

24. Yoo DS, Lee SB, Huh PW, Kang SG, Cho KS. Spinal cord injury in cervical spinal stenosis by minor trauma. World Neurosurg. 2010;73 (3):50-52.

Source of Support: Nil; Conflict of Interest: None

Submitted: 01-02-2019; Accepted: 02-03-2019; Published online: 13-03-2019 